\title{
STUDY ON THE BACTERIAL CELLULOSE PRODUCTION FROM FRUIT JUICES
}

\author{
Maria R. Kosseva ${ }^{1 *}$, Mengmeng Li, Juyan Zhang, Yiting He, Natasia A.S. Tjutju \\ ${ }^{1}$ University of Nottingham Ningbo China (UNNC)
}

\begin{abstract}
Need for large quantity of bacterial cellulose (BC), used as a matrix for production of numerous materials with desirable properties, has increased in the fields of biomedicine and electronics. To achieve the goals further investigations are essential in order to understand the intracellular polymerisation reaction; to increase the biosynthesis rate and reduce cost of the overall production process. Carbon sources for the $\mathrm{BC}$ production are usually glucose, fructose, and sucrose, so juices from low grade fruits can successfully substitute the carbohydrates, vitamins, ascorbic acid, and proteins in the growth medium and can form low-cost substrates. We used strain Gluconoacetobacter xylinus CICC10529 to produce cellulose from watermelon and mandarin juices $(70 \% \mathrm{v} / \mathrm{v}$ and $80 \% \mathrm{v} / \mathrm{v})$ with or without yeast extract supplement. The liquid media (with working volumes $50 \mathrm{~mL}$ and $100 \mathrm{~mL})$ made from fruit juices always contained $\mathrm{MgSO}_{4} \cdot 7 \mathrm{H}_{2} \mathrm{O}(1.5 \mathrm{w} / \mathrm{v} \%)$, $\mathrm{K}_{2} \mathrm{HPO}_{4}(0.1 \mathrm{w} / \mathrm{v} \%)$, as well as ethanol $(1 \mathrm{v} / \mathrm{v} \%)$. Two modes of operation: static biosynthesis in incubator and dynamic biosynthesis in orbital shaker (at $200 \mathrm{rpm}$ ) were conducted at $30^{\circ} \mathrm{C}$. The production process was monitored during 7 to 10 days. Thermal properties of $\mathrm{BC}$ produced at different conditions were investigated through thermal gravimetric analysis and width of the cellulose fibrils/ribbons were compared via microscopic observations.
\end{abstract}

Keywords: Bacterial Cellulose, Fruit Juices, Gluconoacetobacter xylinus

\section{Introduction}

Bacterial cellulose (BC) secreted by the Acetobacter bacteria, so-called "vinegar plant", can be used as a matrix for production of materials with desirable properties. Cellulose produced by bacteria is a promising material for many applications, for example, it can be used for edible packing in the food industry, as wound dressing materials, artificial skin, and scaffolds in regenerative medicine, as electrically conductive paper, and as organic-inorganic hybrid for visible light transmission among others (Shah et al., 2013; Campano et al., 2016). Broad range of the above applications is determined by the particular properties of the $\mathrm{BC}$, which does not have lignin and hemicellulose in comparison to the cellulose derived from plants. Having the identical molecular structure to that of plant cellulose, distinctive properties of $\mathrm{BC}$ are revealed in higher purity, higher crystallinity, higher degree of polymerisation, higher water absorption and retaining capacity, higher tensile strength, and strong biocompatibility. These properties are caused by extremely fine pure fibrils, which form a 3-dimentional network structure (Chen et al., 2010; Lee et al., 2014). The arrangements of fibrils and the conformation of the porous matrix are greatly dependent on several factors: the activity of producing organisms, composition of the culture media, variation in culture time and conditions, amount of the inoculum, and the carbon source (Tang, et al, 2010; Ul-Islam et al., 2016). Watanabe et al. (1998) obtained different structural features and properties of the BC produced under static and agitated culture conditions. The reported $\mathrm{BC}$, which was produced in agitated culture had a lower degree of polymerisation and crystallinity compared with that produced under static conditions.

Kurosumi et al. (2009) studied production of BC varying carbon sources found in the fruit waste and juices. The reported yield of $\mathrm{BC}$ obtained from orange juice was $0.48 \mathrm{~g}$ DW BC from $79.5 \mathrm{~g}$ orange juice.

The aim of this work was to produce $\mathrm{BC}$ using natural complex substrates such as watermelon and mandarin juices

Corresponding Author E-mail: * Maria_Kosseva@yahoo.com

$2^{\text {nd }}$ International Conference on Bioscience and Biotechnology 2017 
at different concentrations. Static and dynamic modes of bacteria cultivations were applied in order to produce matrices with high yield and varied structure. Thermal properties of $\mathrm{BC}$ produced at different conditions were investigated through thermal gravimetric analysis (TGA) and thickness of the fibrils and ribbons produced were compared via microscopic observations.

The watermelon and mandarin juices were chosen for our investigations because of their different contents of carbohydrates, e.g., glucose, fructose, and sucrose, as well as different acidities of the above juices. Thus influence of the juice composition and its acidity on the $\mathrm{BC}$ production was also determined.

\section{Materials and Methods}

\section{Cultivation of Bacteria}

Gluconoacetobacter xylinus strain (CICC 10529) was purchased from China Centre of Industrial Culture Collection, Beijing. It was maintained on glucose agar containing all chemicals described in the CICC growth medium. Plated cultures was stored at $4^{\circ} \mathrm{C}$ in a refrigerator and sub-cultured every 2 months for inoculum development.

CICC growth medium contained: glucose - $20.0 \mathrm{~g}$, yeast extract - $5.0 \mathrm{~g}, \mathrm{~K}_{2} \mathrm{HPO}_{4}-1.0 \mathrm{~g}, \mathrm{MgSO}_{4} .7 \mathrm{H}_{2} \mathrm{O}-15.0 \mathrm{~g}$, and $5 \mathrm{ml}$ of anhydrous ethanol, all components were dissolved in $1.0 \mathrm{~L}$ water purified by reverse osmosis.

\section{Compositions of Media for BC production}

1) Mixture of glucose, fructose, sucrose, yeast extract (FGS), citric acid, ethanol, and mineral salts was used with the following composition: glucose $-2 \mathrm{w} / \mathrm{v} \%$; fructose $-2.5 \mathrm{w} / \mathrm{v} \%$; sucrose $-5.5 \mathrm{w} / \mathrm{v} \%$; citric acid (CA) $-0.12 \mathrm{w} / \mathrm{v} \%$, and ethanol $-0.5 \mathrm{~mL}$ in $100 \mathrm{~mL}$ water at $\mathrm{pH}=5.5$.

2) Sucrose-based medium containing yeast extract, ethanol and mineral salts as follows: sucrose $-5.0 \mathrm{w} / \mathrm{v} \%$, yeast extract $-0.5 \mathrm{w} / \mathrm{v} \%$, ethanol $-1 \mathrm{~mL}$ in $100 \mathrm{~mL}$ water, and mineral salts (SYE).

3) Fruit juices such as watermelon juice (50,70 and $80 \mathrm{v} / \mathrm{v} \%)$ and mandarin juice (70 and $80 \mathrm{v} / \mathrm{v} \%$ ) were studied for the production of BC. Both $80 \mathrm{v} / \mathrm{v} \%$ juice containing media were supplemented only with ethanol, the other medium concentrations (50 v/v and $70 \mathrm{v} / \mathrm{v} \%$ ) contained also yeast extract.

Watermelon juice (WMJ) containing the above mentioned mineral salts in the identical quantities as in the growth medium included also the following components:

a) $50 \mathrm{v} / \mathrm{v} \%$ juice, 0.5 yeast extract $\mathrm{w} / \mathrm{v} \%$, and 0.5 ethanol v/v\%

b) $70 \mathrm{v} / \mathrm{v} \%$ juice, 0.5 yeast extract $\mathrm{w} / \mathrm{v} \%$, and 0.5 ethanol $\mathrm{v} / \mathrm{v} \%$

c) $80 \mathrm{v} / \mathrm{v} \%$ juice and 0.5 ethanol v/v\% in water.

Pure watermelon juice had a $\mathrm{pH}=5.42$.

Mandarin juice (MJ) was used for $\mathrm{BC}$ production, it contained the mineral salts reported and the following components:

a) $70 \% \mathrm{v} / \mathrm{v}$ juice, $0.5 \%$ yeast extract $\mathrm{w} / \mathrm{v}$, and $0.5 \%$ ethanol $\mathrm{v} / \mathrm{v}$ 
b) $80 \% \mathrm{v} / \mathrm{v}$ juice and $0.5 \%$ ethanol $\mathrm{v} / \mathrm{v}$ in water.

Pure mandarin juice had a $\mathrm{pH}=3.75$, it was adjusted to 5 for the biosynthesis process.

Optimal temperature for cultivation of the Gluconoacetobacter xylinus stain was $30^{\circ} \mathrm{C}$. Two modes of operation were performed: static in the incubator and dynamic in the orbital shaker. Duration of each experimental run was 7 days. Static process was investigated in $500 \mathrm{~mL}$ Erlenmeyer flask and working volume of medium $100 \mathrm{~mL}$. It was inoculated with a $\mathrm{BC}$ dose of polymer containing bacteria grown on the surface of the liquid medium in the inoculation tube with size $(\mathrm{R}=1 \mathrm{~cm})$ and dry weight $(\mathrm{DW}=0.02 \mathrm{~g})$.

Dynamic process was carried out in shaker at $200 \mathrm{rpm}$ with inoculum volume $10 \mathrm{v} / \mathrm{v} \%$ of liquid medium. Two volumes of media were used $50 \mathrm{~mL}$ in $250 \mathrm{ML}$ Erlenmeyer flasks and $100 \mathrm{~mL}$ in $500 \mathrm{~mL}$ Erlenmeyer flasks.

Concentrations of bacteria were determined using Chinese version of the McFarland Standards (Pro-Lab Diagnostics) BW2705. Number of bacteria in the inoculation polymer dose was obtained by dissolving it in $10 \mathrm{ml}$ citrate buffer $(\mathrm{pH}=4.7)$ using commercial enzymes (Sigma Aldrich) cellulose $(1 \mathrm{~mL})$ and glucosidase $(1 \mathrm{~mL})$. The average total number was estimated via UV/VIS spectrophotometry and BW2705 calibration standard, it was in the range of 22$25 * 10^{6}$ cells $/ \mathrm{mL}$.

\section{Chemical Analytical Methods}

Total reducing sugar concentrations in the media were analysed via colorimetric the dinitrosalicylic method (DNS) method. Digital refractometer (Ningbo, China) was used to measure sucrose in the fruit juices as Brix \%.

\section{Product Separation}

Separation of the bacterial cellulose products was carried out by filtration. Samples were heated in $100 \mathrm{~mL}$ of $0.1 \mathrm{M}$ $\mathrm{NaOH}$ at $80^{\circ} \mathrm{C}$ for $20 \mathrm{~min}$. Then using vacuum-pump, they were washed with purified water until neutral $\mathrm{pH}=7$. Finally, $\mathrm{BC}$ was dried in the oven at $80^{\circ} \mathrm{C}$ for 5 hours and dry weight was measured until its constant value.

\section{Thermal Gravimetric Analysis}

TGA analyses of BC samples (approx. 10-15mg) were carried out under non-isothermal conditions or dynamic conditions in TG/DTA Apparatus (SII 6300 EXSTAR6000 Japan) with nitrogen flow rate $50 \mathrm{~mL} / \mathrm{min}$ and heating rate $10^{\circ} \mathrm{C} / \mathrm{min}$. A temperature range from $50^{\circ} \mathrm{C}$ to $700^{\circ} \mathrm{C}$ was investigated.

\section{Results and Discussion}

\section{Effect of Carbon Sources}

Evaluation of the carbon source concentrations during the biosynthesis was carried out using DNS method and the results obtained are shown in Figures 1 and 2. Total reducing sugars in the synthetic media containing glucose, sucrose, and fructose were consumed following 6-7 days of the dynamic cultivation, whereas their depletion in the fruit juices (e.g., mandarin juice) was twice quicker as shown in Figure 2. This can be explained by the higher affinity of the bacteria to glucose and fructose containing media compare to the sucrose, which contents was also measured in the fruit juices. The fastest consumption of carbon source and BC production process was observed in the shaker (3 days), whereas slower biosynthesis was recorded in the incubator (4 days) at identical other conditions. 

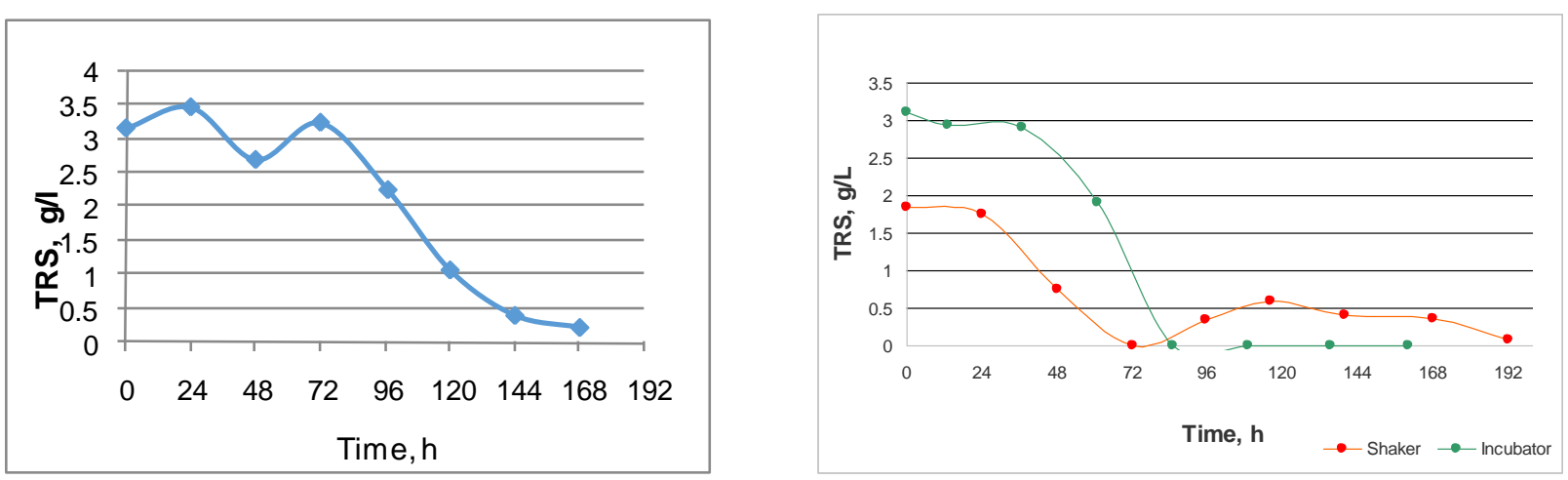

Figure 1. Variation of [TRS] in the FGS medium.

Figure 2.Variation of $[\mathrm{TRS}]$ in $80 \mathrm{v} / \mathrm{v} \%$ mandarin juice

The Gluconoacetobacter xylinus strain (CICC 10529) was able to produce BC from the fruit juices like watermelon and mandarin without any protein additions under the conditions described above. It was possible because watermelon and mandarin naturally contains nitrogen sources, which can enhance bacterial growth without supplements.

\section{Yields and Productivities}

The BC yield and productivity varied substantially at different conditions. As shown in Fig. 3, the highest yield based on dry weight (DW $=16.4 \mathrm{~g} / \mathrm{L}$ ) was obtained from $70 \mathrm{v} / \mathrm{v} \%$ watermelon juice supplemented with yeast extract during the dynamic cultivation, then $80 \mathrm{v} / \mathrm{v} \%$ watermelon and $80 \mathrm{v} / \mathrm{v} \%$ mandarin juices with ethanol additions gave yields approx. 12 and $11 \mathrm{~g} / \mathrm{L}$ on DW basis, respectively. From the synthetic media high yield was produced using sucrose-based medium (about $14 \mathrm{~g} / \mathrm{L}$ of DW) during the dynamic biosynthesis.

The highest BC productivity was achieved during the dynamic biosynthesis in the media containing yeast extract (up to $3.0 \mathrm{~g} \mathrm{DW} / \mathrm{L} . \mathrm{d})$ and in $80 \%$ WMJ without yeast extract (YE) supplement (2.0 g DW/L.d), referred to Table 1. During the static biosynthesis, productivity of the $\mathrm{BC}$ varied from 0.80 to $1.10 \mathrm{~g}$ DW/L.d in the watermelon and mandarin juices, respectively.

Table 1 . The productivity of the $\mathrm{BC}$ production via dynamic biosynthesis.

\begin{tabular}{lllllll}
\hline $\begin{array}{l}\text { Medium used } \\
\text { for } \\
\begin{array}{l}\text { dynamic BC } \\
\text { production }\end{array}\end{array}$ & $\begin{array}{l}\text { Glucose,YE, } \\
\text { EtOH }\end{array}$ & $\begin{array}{l}\text { FGS,CA, } \\
\text { EtOH }\end{array}$ & $\begin{array}{l}\text { Sucrose, YE, } \\
\text { EtOH }\end{array}$ & $\begin{array}{l}50 \% \text { WNJ,YE, } \\
\text { EtOH }\end{array}$ & $\begin{array}{l}70 \% \text { WMJ,YE, } \\
\text { EtOH }\end{array}$ & $\begin{array}{l}\text { 80\%WMJ, } \\
\text { EtOH }\end{array}$ \\
\hline $\begin{array}{l}\text { Productivity, } \\
\text { g DW/ L.d }\end{array}$ & 1.20 & 1.42 & 2.0 & $1.40-1.70$ & $2.4-3.0$ & $1.50-2.0$ \\
\hline
\end{tabular}




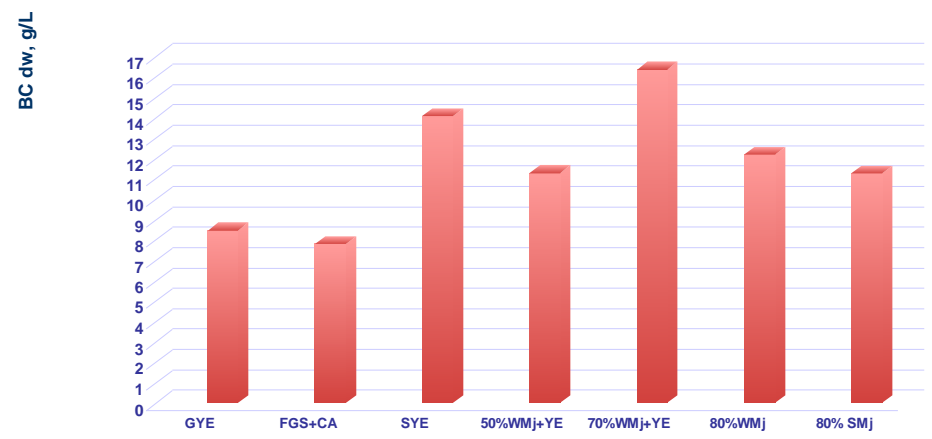

Type of Medium

Figure 3. The yields of the $\mathrm{BC}$ produced via dynamic biosynthesis in different media.

\section{Thermal Analysis}

We studied thermal properties of various BC matrices using TGA analysis. Differences in the weight loss of the BC samples under non-isothermal conditions at the temperatures studied were recorded by the TG/DTA apparatus. The weight [(initial sample weight -incidental sample weight)/initial sample weight] in \%) versus temperature were plotted for the dynamic and static modes of cultivation, they are depicted in Figures 4 and 5. Final amount of material detected at the temperature of $700^{\circ} \mathrm{C}$ was equal to $25 \%$ in the shaker and $15 \%$ in incubator. The thermal curves of the BC produced from the glucose-based synthetic medium and $80 \mathrm{v} / \mathrm{v} \%$ watermelon juice followed similar paths at the same dynamic conditions. However, the BC produced in the static process performed differently. A well-pronounced step in the weight loss was observed at the inset temperature of 250 to outset temperature of $400^{\circ} \mathrm{C}$, the weight loss was equal to about $50 \%$ of the $\mathrm{BC}$. This dramatic change was not found during the dynamic cultivation where smooth weight loss was around $40 \%$ at the same temperatures. The BC produced from fruit juices exhibited even smaller changes in the weight (in the range of 15-30\%) at the identical temperatures recorded. Final weight $\%$ of the samples measured at $\sim 700 \mathrm{oC}$ was equal to $25 \%$ of their initial weight produced in the dynamic mode, and $15 \%$ - in the static mode. These events could be explains by the variation of BC morphology in the samples, e.g. different width and size of the fibrils/ribbons produced under different modes of the bacterial cultivations.

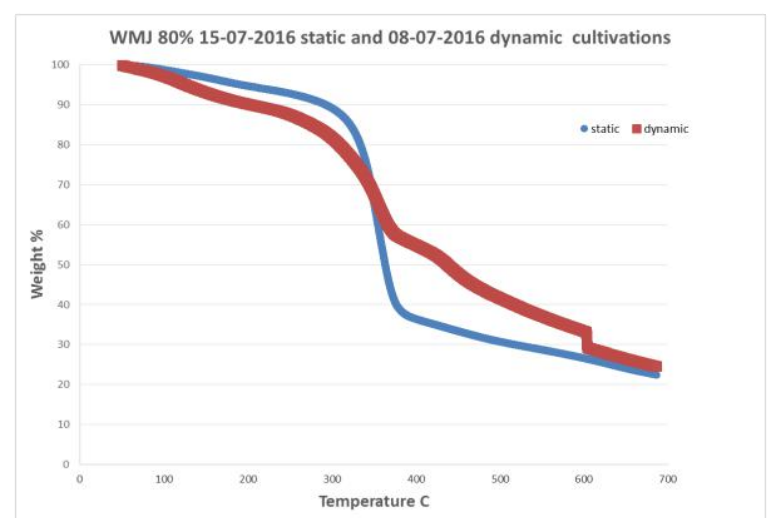

Figure 4. TGA of the WMJ samples produced in static dynamic modes.

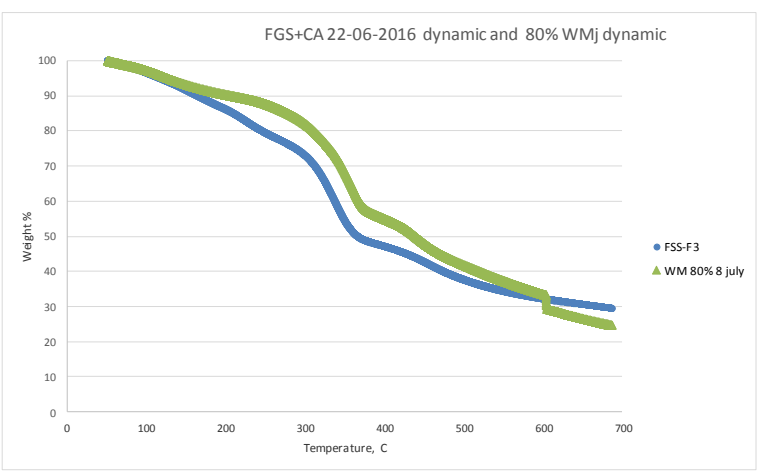

Figure 5. FGS and WMJ samples produced in the dynamic mode. 


\section{Static versus Dynamic Growth}

Morphological changes of the BC fibrils produced statically and dynamically were reported previously by Watanabe et al. (2009). The authors examined scanning electron micrographs of BC and found that fibrils produced sin static culture were more highly extended and had larger width. Whereas, fibrils of the BC produced under agitated conditions were curved and entangled with each other resulting in a denser reticulated structure than those of the static BC. The width of the fibrils produced dynamically appeared smaller than that of the static fibrils. Our microscopic observations showed analogous results, which illustrates lower width of the dynamically produced BC fibrils, and respectively, ribbons formed from those fibrils compare with the statically produced structures. As shown in Figures 6 and 7, the average width of the ribbons (around 28 microns) was produced in the shaker from mandarin juice. In the same time ribbons with average width of approx. 40 microns were synthesized under the static conditions. SEM observations also showed denser morphological structure with smaller width of the BC fibrils produced in the dynamic mode than those produced in the static mode (Figures 8 and 9).

Figure 6. Size of the BC ribbons observed by the light microscopy (x400) in $80 \%$ SMJ of dynamic cultivation.

Figure 7. Size of the BC ribbons observed by the light microscopy (x400) in $80 \%$ SMJ in the static incubator.

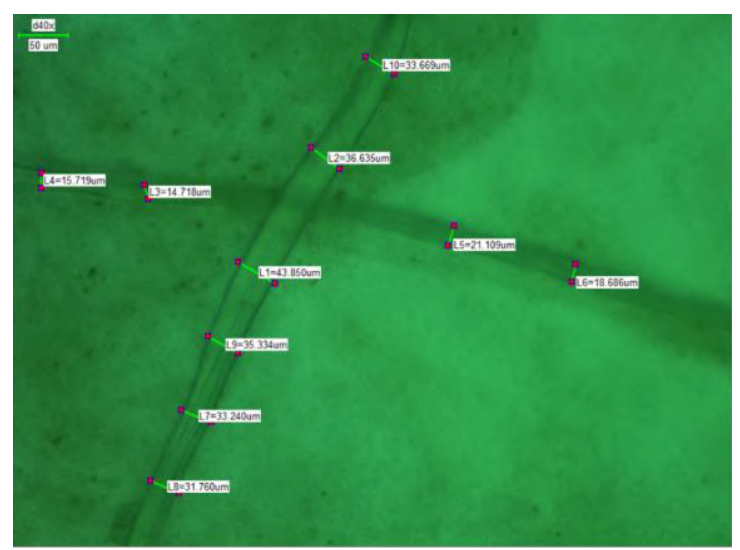

Figure 6.

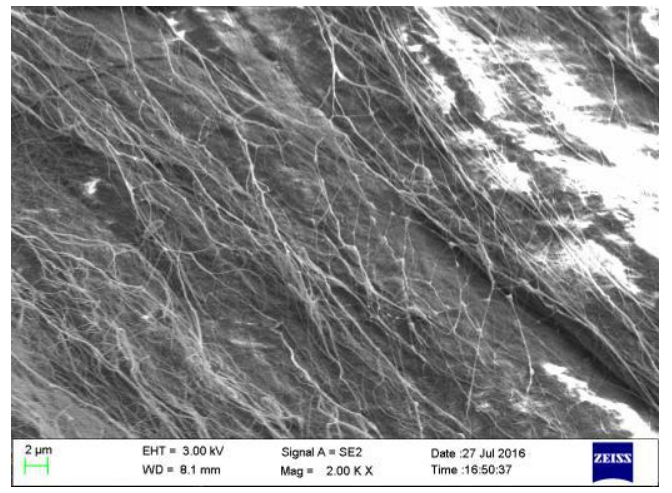

Figure 8. Sample of $80 \%$ WMJ- dynamic mode.

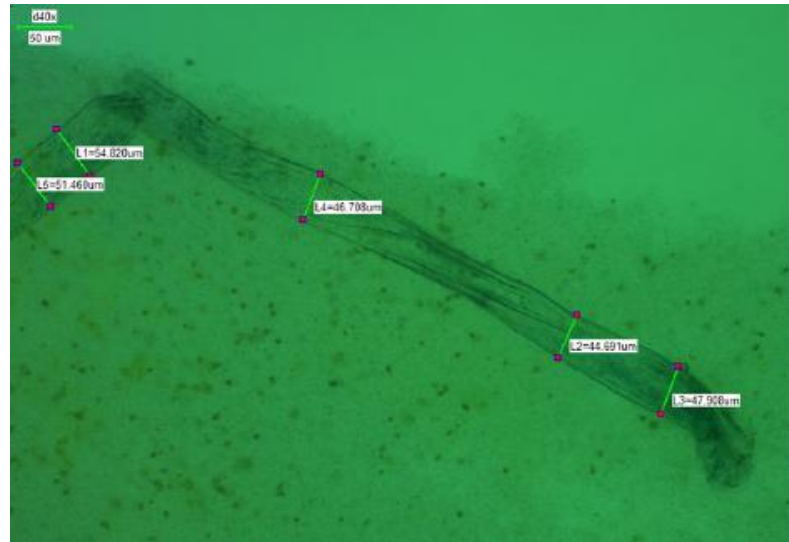

Figure 7.

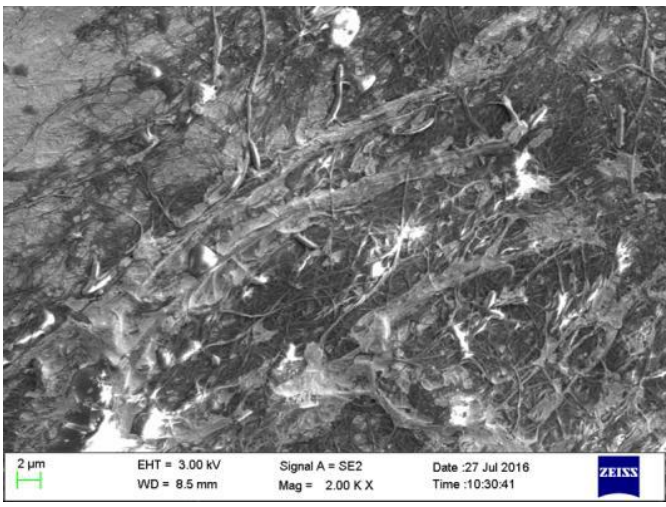

Figure 9. Sample of $80 \% \mathrm{WMJ}$ - static mode. 


\section{Conclusions}

Juices from selected fruits, for example, watermelon and mandarin juices can be successfully used as growth media for the Gluconoacetobacter xylinus bacteria. With no addition of nitrogen source they can provide affordable carbon sources and nutrients for production of the BC.

Using different modes of operation: under the static and dynamic cultivations of the bacteria, the BC fibrils and ribbons with diverse width and density were produced. The ribbon width produced in the shaker was approx. 25-37 microns after 2 days, however, the larger width was found in the BC produced in the incubator ( 40 -50 microns) during the same production time. This morphology was responsible for the different thermal behaviour of the $\mathrm{BC}$ samples, when non-isothermal heating was applied in the dynamic nitrogen environment, increasing temperature

from 50 to $700^{\circ} \mathrm{C}$. Ten percent higher thermal stability was exhibited by the $\mathrm{BC}$ samples produced via the dynamic mode.

\section{References}

Campano, C., Balea, A., Blanko, A., Negro, C., 2016, Enhancement of the fermentation process and properties of bacterial cellulose: a review, Cellulose, 23, 57-91.

Chen, P., Cho, S.Y., Jin, H.-J., 2010, Modification and applications of BC in Polymer Science, Macromol Research, 18(4), 309-320.

Kurosumi, A., Sasaki, C., Yamashita, Y., Nakamura, Y., 2009, Utilization of various fruit juices as carbon source for production of bacterial cellulose by Acetobacter xylinum NBRC 13693. Carbohydr Polym 76, 333-335.

Lee, K.-Y., Buldum, G., Mantalaris, A., Bismarck, A., 2014, More Than Meets the Eye in Bacterial Cellulose: Biosynthesis, Bioprocessing, and Applications in Advanced Fiber Composites, Macromol. Biosci., 14, 10-32.

Shah, N., Ul-Islam, M., Khattak, W. A., Park, J. K., 2013, Overview of bacterial cellulose composites: A multipurpose advanced material. Carbohydrate Polymers, 98, 1585-1598.

Tang, W., Jia, S., Jia, Y., Yang, H., 2010, The influence of fermentation conditions and post-treatment methods on porosity of bacterial cellulose membrane. World Journal Microbiology and Biotechnology, 26, 125-131.

Ul-Islam, M., Khan, T., \& Park, J. K., 2012, Water holding and release properties of bacterial cellulose obtained by in situ and ex situ modification. Carbohydrate Polymers, 88, 596-603.

Watanabe, K., Tabuchi, M., Morinaga, Y., Yoshinaga, F., 1998, Structural features and properties of bacterial cellulose produced in agitated culture. Cellulose, 5, 187-200. 